\title{
Storylines of institutional responses to climate change as a transformative stressor: the case of regional planning in south east queensland, australia
}

\author{
TONY MATTHEWS \\ School of Civil Engineering and Built Environment, \\ Queensland University of Technology, \\ 2 George Street, \\ GPO Box 2434, \\ Brisbane, Queensland 4001, \\ Australia \\ Phone: +61 (7) 31381188 \\ Email: tony.matthews@qut.edu.au
}

\begin{abstract}
Institutional responses to climate change stresses through planning will require new and amended forms of governance. Institutional framing of change imperatives can significantly condition associated governance responses. This paper builds on scholarly conversations concerning the conceptual role of 'storylines' in shaping institutional responses to climate change through governance. It draws on conceptual perspectives of climate change as a 'transformative stressor', which can compel institutional transformation within planning. The concepts of storylines and transformative stressors are conceptually linked. The conceptual approach is applied to an empirical enquiry focused on the regional planning regime of South East Queensland (SEQ), Australia. This paper reports and examines three institutional storylines of responding to climate change through planning governance in SEQ. It concludes that the manifestation of climate change as a transformative stressor in SEQ prompted institutional transformation, leading to a dominant storyline focused on climate adaptation as an important facet of regional planning governance.
\end{abstract}

Keywords: Storylines, transformative stressors, institutions, governance, climate change, regional planning 


\section{Introduction}

Responding to climate change stresses represents a nascent and vital institutional challenge for planning (Bulkeley et al., 2009; IPCC, 2007). Anxieties over future climate change impacts are rapidly and forcefully encroaching on the discipline of planning and substantive institutional responses must be delivered through governance processes (Gleeson, 2008; Matthews, 2012). Planning regimes correspond to social scientific characterizations of institutions as they utilize governance processes to direct, regulate and shape spatial identities and materialities (Alexander, 2005; Healey, 2006). Emerging institutional challenges like climate change may be at odds with existing institutional planning governance. Institutional transformation, leading to new forms of planning governance, may be required in order to manage the stresses and impacts associated with new planning challenges (Alden, Albrechts and da Rosa Pires, 2001; Alexander, 2005; Matthews 2012). The ways in which planning regimes institutionally frame new change imperatives may significantly condition the nature and character of governance responses.

This paper adds to existing scholarly conversations in Environment and Planning $C$ (Bulkeley, 2000; Fisher, 2012; Lovell, Bulkeley and Owens, 2009), which focus on responses to climate change through the development and delivery of new or amended forms of governance. These conversations focus on the role of institutional 'storylines' in framing governance responses to environmental challenges by allowing institutional actors to conceptualize particular change imperatives (Hajer, 1993; 1995). This paper seeks to build on these conversations by providing further conceptual and empirical insights into how storylines can condition institutional responses to climate change through planning governance. Its conceptual content applies Hajer's $(1993,1995)$ storylines model to a recent model of institutional transformation proposed by Matthews (2012), which illustrates how 'transformative stressors' may lead to the creation of new forms of institutional governance. It is argued that institutions can interpret and respond to transformative stressors through storylines, as storylines are used to create descriptions of particular transformative stressors and their impacts. The empirical content of this paper focuses on a case study of regional planning in South East Queensland (SEQ), Australia, between 1992 and 2012. It reports how climate change was institutionally interpreted through three institutional storylines within the SEQ regional planning regime and how its eventual manifestation as a transformative stressor led to the emergence of climate adaptation as a tenet of regional planning governance.

\section{The nexus between transformative stressors, storylines and institutional transformation}

The nature and character of institutions as social scientific objects has been the subject of extensive scholarly debate (Hodgson, 2006; Kingston and Caballero, 2009; March and Olsen, 2005; North 1990). Institutions are socially important because a significant volume of modern governance occurs through them (Healey, 2006; Kingston and Caballero, 2009). Scholarship understands that institutions guide social behavior through the creation and imposition of rules that provide stable social structures, which facilitate human interaction in social, economic and political contexts (Hall and Taylor, 1998; Kingston and Caballero, 2009; Levi, 1990; March and Olsen, 2005; North, 1990; 1993). For example, policies are an expression of institutional governance and exist to structure the relationship between state officials and societal actors (Cortell and 
Peterson, 1999; Young, 2002). Planning is a set of strategic endeavors which function as governance processes, designed to spatially shape the materialities and identities of particular spaces and places (Forester, 1989; Giddens, 1984; Healey, 1998). Accordingly, planning regimes correspond to social scientific characterizations of institutions.

An important characteristic of institutions is their capacity for transformation. Institutional transformation occurs when an institution amends governance in order to try and deliver improved social outcomes (Alexander, 2005; Kingston and Caballero, 2009; North, 1993). A capacity for transformation is fundamental within institutions, as shifting social conditions can produce change imperatives which create demands for new, improved or amended forms of governance (Hogan, 2006; Matthews, 2012; Young, $1999 ; 2002 ; 2012)$. Institutional transformation generally occurs when an institution is faced with particular stresses that are not easily managed through existing rules of governance. Affected institutions can respond by undergoing transformative processes aimed at amending existing governance to deliver improved social outcomes (Alexander, 2005; Cortell and Peterson, 1999; Kingston and Caballero, 2009). This paper draws upon a new conceptualization of institutional transformation, which is based on the proposition that certain stressors possess sufficient capacity to compel institutional transformation, due to the severity, longevity and escalation of their associated impacts. These stressors are referred to as 'transformative stressors' (Matthews, 2012).

A transformative stressor is characterized as a chronic large-scale phenomenon which triggers a process of institutional transformation whereby institutions seek to reorientate, reorganize and restructure their activities in order to better manage the social, economic and environmental impacts created by the transformative dynamic (Matthews, 2012). Three points are of note in defining and characterizing a transformative stressor. First, the stressor must be chronic, meaning that it must present a combination of social, environmental and economic impacts that are acute, severe and intense. Second, transformative stressors may be multi-scalar, occurring at global, transnational, national, regional and, in limited circumstances, local spatial scales. They may also occur across systemic scales, meaning that a single transformative stressor may impact upon more than one institution. Affected institutions may be spatially separated with vastly different institutional priorities or may be closely located and similarly orientated. Third, the temporal impact of transformative stressors is generally expected to occur in the medium to long term. Short-term institutional inaction will likely prolong the challenge of managing a transformative stressor and increase the level of response required later.

This paper focuses on anthropogenic climate change as a transformative stressor within the institutional context of planning. Climate science demonstrates that the phenomenon is large-scale and its impacts will escalate, with potential to generate many different forms of stress at national, regional and local levels (CSIRO, 2012; IPCC, 2007; 2012; Steffen, 2009). Predicted impacts include: damage to physical infrastructure; extreme weather events; escalating economic costs; social upheaval; physical harm to natural and man-made environments; biodiversity losses; and resource reductions (Garnaut, 2008; IPCC, 2007; Stern, 2006). Climate change is a transformative stressor as its incidence and impacts will occur across institutional, 
spatial and temporal scales. It is a long-term challenge, as impacts will continue to occur even if greenhouse gas emissions stopped abruptly, due to historical emissions currently locked in the atmosphere (CSIRO, 2012; 2011; IPCC, 2007). Climate change will create substantial cost impacts if left unaddressed and these are likely to eventually challenge cost tolerability (Stern, 2006). Climate change is fundamentally different from most other stress phenomena faced by institutions. Its impacts are predicted to be chronic and will be acutely felt across human and natural systems. These have the potential to become critical in some cases. This paper understands climate change response as an urgent institutional agenda for planning, requiring institutional transformation to deliver institutional responses that establish mitigation and adaptation as central tenets of planning governance.

Scholarship has extensively debated how institutional change processes may be constituted and transmitted (Bulkeley, 2000; Fisher, 2012; Hajer, 1993; 1995; Lovell, Bulkeley and Owens, 2009; Low, Gleeson and Rush, 2003; Young, 2002; 2010). The conceptual model of 'storylines' presented by Hajer $(1993,1995)$ has been proposed as a means of understanding why institutional transformation did or did not occur in particular cases. Hajer characterizes storylines as social narratives "through which elements from many different domains are combined and that provide actors with a set of symbolic references that suggest a common understanding" (1995, page 62). They can fulfill an essential role in directing institutional discourse by clustering knowledge and positioning actors. Groups of actors who subscribe to particular storylines may form 'discourse coalitions', which are characterized by collections of storylines, the actors who subscribe to them and the institutional practices through which elements of associated narratives are espoused (Hajer 1995, page 65). Storylines can facilitate or block the development of new institutional governance, making them "prime vehicles of change" (Hajer 1995, page 63).

Hajer $(1993,1995)$ developed the storylines concept to test how particular narratives conditioned institutional change in respect of the emergence of ecological modernization as an environmental language used to address the acid rain phenomenon in the UK and the Netherlands. These analyses show that storylines influence institutional transformation by discursively framing specific issues and establishing them as compelling institutional narratives. New institutional change imperatives can be blocked or advanced by particular storylines if the storylines gain sufficient traction to influence institutional decision-making. Particular storylines can strongly condition institutional transformation by attaching meaning to circumstances and allowing institutional actors to conceptualize or re-conceptualize both general and specific facets of particular change imperatives. Hajer's storylines model is widely regarded in scholarship. For example, it is used to examine how four energy and climate change storylines emerged in the UK energy sector and drove institutional transformation, resulting in varying degrees of policy reorientation (Lovell, Bulkeley and Owens, 2009). The model is employed by Fisher (2012) as a means of examining the articulation of policy discourses through storylines within Indian climate politics. Bulkeley (2000) uses storylines to examine how policy problems connected to climate change were delineated and conceptualized through the Australian climate change policy network. Bulkeley's work focuses closely on the linkages between actors operating at different scales of governance and specific storylines. A key finding is that the nature and form of institutional responses to climate change through policy learning 
and articulation was strongly conditioned by the manifestation and growth of specific storylines which in turn attracted or repelled institutional actors.

Hajer's (1993; 1995) storylines model is applied via Matthews' (2012) transformative stressors model in this paper (see Figure 1). Consequently, institutional recognition, acceptance and response to transformative stressors are understood to relate to their articulation through storylines. Institutions and institutional actors can interpret and respond to transformative stressors through storylines, as storylines create descriptions of particular transformative stressors and their impacts. This paper proceeds on the basis that transformative stressors possess strong capacity to influence the nature and form of institutional transformation processes by generating, removing or re-orientating institutional storylines. The extent of support for particular storylines amongst institutional actors can strongly influence which storylines lead to governance responses. It holds that the degree of institutional support for specific storylines, even when multiple storylines relate to the same transformative stressor, means that those with most support are likely to dominate institutional responses through governance. However, there remains a possibility for new transformative stressors and associated storylines to emerge. A new transformative stressor may displace or relegate existing storylines because the new stressor and its storylines may gain greater priority amongst a majority of institutional actors.

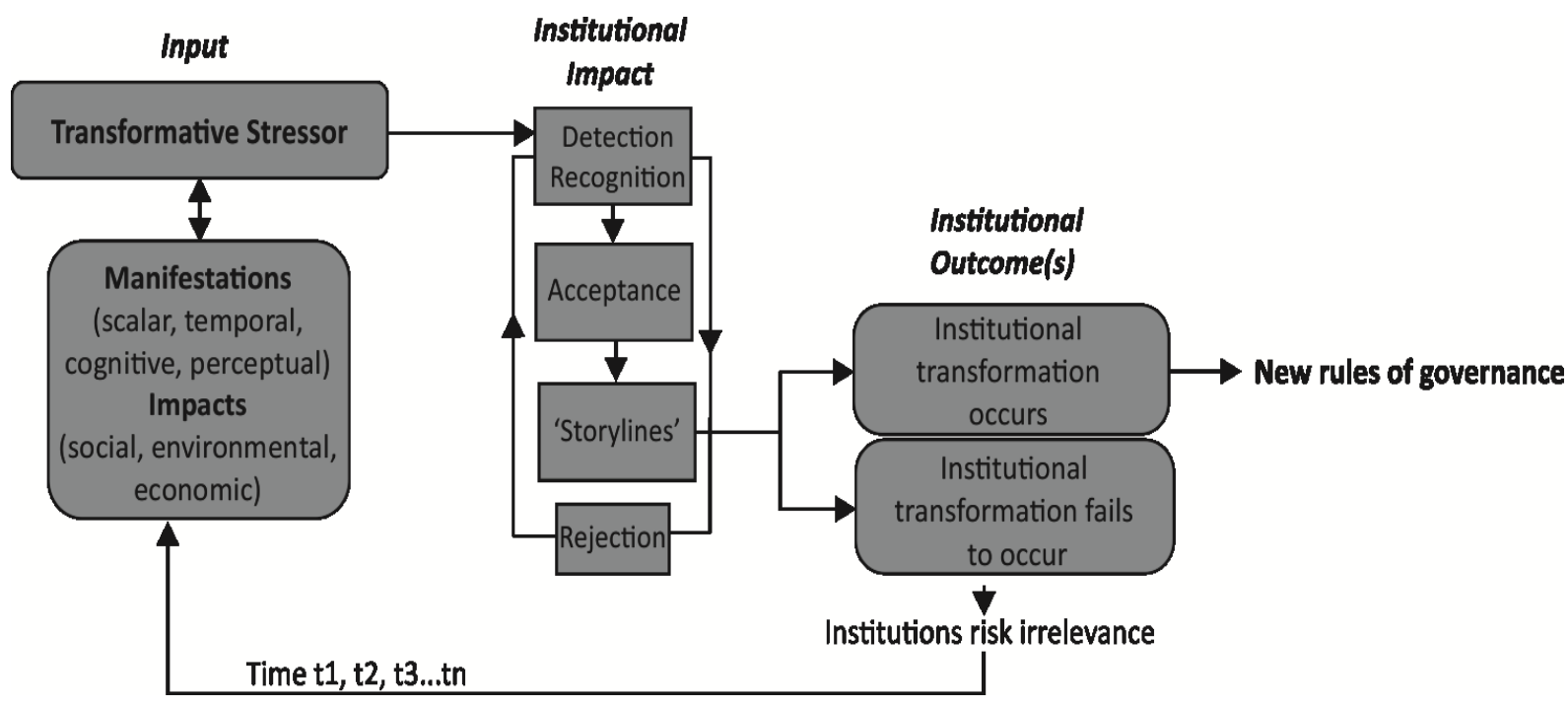

Figure 1: Transformative stressors and storylines flow diagram

\section{Methods}

The storylines model has been used widely in scholarship, yet there are no formal methodological processes used to identify and characterize particular storylines. Consequently, this paper advances a new methodological approach for identifying storylines. It utilizes the work of Yanow (2000), which focuses on conducting interpretive policy analysis and deconstructing the architecture of policy arguments by examining how language, symbolic relationships, culture and group processes can individually or cumulatively condition particular policy outputs or expressions. Yanow's work focuses "on the meanings of policies, on the values, feelings of beliefs they express and the processes by which those meanings are communicated to and read by various audiences" (2000, page 14). This paper applies Yanow's (2000) interpretive approach to 
Hajer's $(1993,1995)$ storylines model and adopts the position that storylines, as a means of discursively framing certain issues, condition institutional positions and outputs in the same way as policy outputs. Therefore, particular storylines communicate institutional positions, which in turn condition the nature, extent and character of institutional responses to specific imperatives, including transformative stressors. As these responses tend to manifest through the imposition of institutional governance, it becomes possible to identify storylines through a process of examining specific institutional governance outputs.

Research focused on identifying relevant storylines from the South East Queensland (SEQ) case study took place between 2010 and 2102. It utilized Yanow's approach to interpretive policy analysis in order to identify policy artifacts that were significant in conveying particular institutional perspectives related to climate change. A program of thematic textual analysis was undertaken for to identify key institutional storylines which appeared to give meaning to the nature and character of specific issues addressed over time by regional planning in SEQ. The storylines relevant to this paper were identified through a thematic reading of approximately 170 institutional texts which were sourced using a 'purposeful' approach (Patton, 1990). Selected texts included planning policy documents, information papers, working governmental reports, framework documents, minutes from meetings of peak SEQ planning agencies, as well as statutory and non-statutory regional plans (see Figure 2). The texts were coded by hand as many were only available in hard copy and therefore could not be imported into coding software. The coding process was designed to identify and characterize emergent, evolving and abandoned institutional storylines with respect to responding to climate change through regional planning. This generated a characterization of over-arching institutional storylines that appeared to condition institutional responses.

\begin{tabular}{|c|c|c|c|}
\hline Publisher & Paper Type & Date & $\begin{array}{c}\text { Numbe } \\
\mathbf{r}\end{array}$ \\
\hline $\begin{array}{l}\text { Regional Planning Advisory Group } \\
\text { (RPAG) }\end{array}$ & Position Paper & 1992 & 2 \\
\hline RPAG & Information Paper & 1993 & 5 \\
\hline RPAG & Policy Paper & 1993 & 15 \\
\hline RPAG & Evaluation Paper & 1993 & 2 \\
\hline RPAG & Working Report & 1993 & 2 \\
\hline RPAG & Regional Planning Report & 1993 & 1 \\
\hline RPAG & Final Report \& Recommendations & 1994 & 1 \\
\hline RPAG & Minutes & 1991-1994 & 18 \\
\hline Regional Coordination Committee (RCC) & $\begin{array}{l}\text { SEQ Regional Framework for Growth } \\
\text { Management }\end{array}$ & 1995 & 1 \\
\hline RCC & Memorandum of Agreement & 1995 & 1 \\
\hline RCC & $\begin{array}{l}\text { SEQ Regional Framework for Growth } \\
\text { Management }\end{array}$ & 1996 & 1 \\
\hline RCC & $\begin{array}{l}\text { SEQ Regional Framework for Growth } \\
\text { Management }\end{array}$ & 1998 & 1 \\
\hline RCC & $\begin{array}{c}\text { SEQ Regional Framework for Growth } \\
\text { Management }\end{array}$ & 2000 & 1 \\
\hline RCC & Information Paper & 2002 & 1 \\
\hline RCC & Discussion Paper & 2003 & 4 \\
\hline RCC & Minutes & 1994-2009 & 64 \\
\hline Regional Resource Unit (RRU) & Discussion Paper & 1998 & 1 \\
\hline $\begin{array}{c}\text { Department of Local Government, } \\
\text { Planning, Sport and Recreation (DLGPSR) }\end{array}$ & Draft SEQ Regional Plan & 2004 & 1 \\
\hline
\end{tabular}




\begin{tabular}{|c|c|c|c|}
\hline DLGPSR & SEQ Regional Plan & 2005 & 1 \\
\hline DLGPSR & Strategic Plan & 2006 & 1 \\
\hline $\begin{array}{l}\text { Department of Infrastructure and } \\
\text { Planning (DIP) }\end{array}$ & Strategic Plan & $2007-2012$ & 5 \\
\hline DIP & SEQ Regional Plan & 2009 & 1 \\
\hline DIP & Draft SEQ Regional Climate Change Plan & 2009 & 1 \\
\hline Regional Planning Committee (RPC) & Minutes & $2010-2011$ & 8 \\
\hline Council of Mayors (COM) & Minutes & $2006-2012$ & 34 \\
\hline $\begin{array}{l}\text { Department of State Development, } \\
\text { Infrastructure and Planning (DSDIP) }\end{array}$ & Policy Paper & 2012 & 1 \\
\hline
\end{tabular}

Figure 2: Texts reviewed during research

The context, background and validity of the identified storylines were subsequently tested through a program of semi-structured interviewing. Interview requests were sent to 18 potential respondents, of which 14 agreed to participate - a positive response rate of $78 \%$. Interviews took place with senior state and local government planners, policy makers, politicians, as well as community and environmental representatives who were closely involved with SEQ regional planning during the 1990s and 2000s (see Figure 3). Respondents were asked to discuss the storylines identified through textual analysis and to provide insights into the nature of associated institutional responses, including formal responses through planning governance. The average duration of each interview was one hour. The interview audio was transcribed and coded in each instance. A limitation of the interviewing process is that that much of the focus was on past events, which may have had bearing on the accuracy of some respondent's recollections. Bias was another potential limitation. As there is a human involvement in all forms of qualitative research, there is a danger that bias may influence the process and findings. Every effort was made to avoid bias and manage objectivity by strictly adhering to research rigor while collecting data (Flick, 1998, page 231-232; Sarantakos, 2005, page 19-20).

\begin{tabular}{|c|c|}
\hline $\begin{array}{l}\text { Interview } \\
\text { Respondent } \\
\text { (IR) }\end{array}$ & Occupation (Generic occupation descriptions provided by each respondent) \\
\hline IR1 & Senior State Government Planner, 1989-2010 \\
\hline IR2 & Senior Director of SEQ Regional Planning, 1990-2012 \\
\hline IR3 & $\begin{array}{c}\text { Long-standing representative of professional planning in the SEQ regional planning process, } \\
\text { 1990-present }\end{array}$ \\
\hline IR4 & Environmental Organizer \\
\hline IR5 & Senior representative of a regional environmental advocacy group \\
\hline IR6 & Queensland State government policy advisor, 2002-present \\
\hline IR7 & $\begin{array}{l}\text { SEQ Regional Planning Policy Advisor; Chair of Council of Australian Governments (COAG) } \\
\text { Working Group on Climate Change Adaptation }\end{array}$ \\
\hline IR8 & SEQ Regional Organization of Councils (SEQROC) Coordinator, 1994-2006 \\
\hline IR9 & Regional Planner with SEQ Council of Mayors (COM) \\
\hline IR10 & Executive Director of Planning Policy, Department of Local Government and Planning (DIP) \\
\hline IR11 & Mayor of Noosa Council 1997-2008; Sunshine Coast Regional Council 2008-2012 \\
\hline IR12 & Former Director at the Department of State Development, Infrastructure and Planning (DSDIP) \\
\hline IR13 & $\begin{array}{c}\text { Planner involved in the South East Queensland Regional Plans 2005-2026 \& 2009-2031 and } \\
\text { Draft South East Queensland Climate Change Management Plan 2009 }\end{array}$ \\
\hline IR14 & Regional Planner with Queensland Government \\
\hline
\end{tabular}

Figure 3: Interview respondents

\section{Storylines of climate change in South East Queensland regional planning}


South East Queensland (SEQ) is a heavily urbanized sub-tropical region on Australia's east coast. Settlement patterns are concentrated in two conurbations. One runs along the coastline for 200 kilometers and includes Brisbane and Gold Coast City, Australia's third and sixth largest cities. The second major conurbation runs inland from the coast, via Brisbane, to the city of Toowoomba in the west. The region has rapidly expanded since the 1970s, principally due to rapid inward population growth driven by international migration as well as domestic migration from other Australian states (Abbott, 2009). The population of SEQ rose from 1.5 million to 2.5 million between 1979 and 2004 and is forecast to grow to as much as 4.4 million by 2031 (DIP, 2009a, page 8). Growth pressures have impacted heavily on the region's natural environment. Future and continuing growth pressures, along with climate change impacts, will exacerbate regional environmental stresses (Hennessey et al. 2007, page 525).

Australia has a three-tier system of governance, with Commonwealth, State and local levels of government. The Commonwealth rarely engages directly in spatial planning activities and generally leaves State and local governments to establish and implement appropriate frameworks between them (Abbott, 2009). The SEQ regional planning regime is one such example. It is based on a partnership arrangement between the State government of Queensland and the 11 local councils of SEQ (DIP, 2009a). The regime gained statutory footing in 2004, having operated on a collaborative and nonstatutory basis since 1990. The statutory framework requires that all planning activities, regulations, strategies and interventions implemented by the local councils in SEQ must correspond with institutional planning objectives established through regional plans and frameworks. Discussions focused on identifying and developing institutional responses to new or ongoing institutional planning priorities in SEQ usually take place within the meetings of peak planning agencies. Current peak planning agencies include the Regional Planning Committee (RCC) and the SEQ Council of Mayors (COM). The RPC was formerly known as the Regional Coordination Committee (19942010) and Regional Planning Advisory Group (1900-1994). The COM was formally known as the SEQ Regional Organization of Councils (1991-2005).

Storyline 1: Climate change is an important regional planning challenge for SEQ and must responded to through planning activities, processes and instruments

Climate change first gained institutional recognition within SEQ regional planning in the 1990s. The phenomenon was discussed amongst some of the region's local councils at the time, principally in response to representations from conservation groups. However, it was not recognized as a significant planning concern and was not articulated through institutional storylines. The fact that it failed to gain greater institutional traction when first identified as a potential planning issue may be due to the fact that it had not yet generated specific stresses for SEQ. Climate change was viewed as a distant problem by the SEQ planning regime during the 1990s and was discussed in the abstract. The relational dimension of climate change, as articulated through storylines within the institutional context of planning at the time, appears to have viewed the phenomenon as relatively disconnected from planning activity. The temporal dimension of climate change also viewed the issue as a distant problem that did not warrant immediate attention. Placed within the context of the transformative stressors framework, it may be argued that the lack of manifest social, environmental or economic impacts in SEQ meant that climate change was institutionally detected but 
failed to generate responses due to a lack of impacts in the 1990s. Interview Respondent IR3, a long-standing professional representative of SEQ regional planning, noted:

There were discussions about climate change going on in the 90s, but they weren't really influencing regional planning...climate change wasn't really seen as a big issue, it was just something else you might have to do something about. Then it faded a bit, before coming back in the early-2000s.

Climate change re-emerged as a planning issue in SEQ in the early-2000s. Discussions were held by the Regional Coordination Committee (RCC), a peak SEQ regional planning advisory committee, to identify and develop responses to nascent regional planning challenges. The RCC discussions marked the beginning of institutional recognition of climate change as a planning issue in SEQ. This was partly influenced by broader discussions within political and public circles, which recognized the emerging challenges of climate change, its potential impacts and need to respond. The RCC discussions were identified by interview respondent IR1, a senior state government planner from 1990-2010, as central to establishing climate change as an institutional storyline:

We [the RCC] did this scoping exercise of identifying new policy areas that we hadn't dealt with...we identified eleven topics and set up groups to investigate them. Greenhouse was one of those topics and we started to look at it.

The growing institutional recognition of climate change generated a new institutional storyline that framed climate change as an important regional planning issue for SEQ, requiring a variety of planning responses. However, support for the storyline appears to have initially been stronger in local governments than in the State government. Indeed, many local councils in the region were already pursuing climate change policies and initiatives and some already had their own local level response programs. Consequently, local councils began to encourage the State government to commit to policy settings within regional planning processes. Interview Respondent IR10, an Executive Director of Planning Policy at the Department of Local Government and Planning, stated:

There was recognition by government that it needed to deal with climate change [but] admitting that it is going to happen is a bit difficult politically. There was a sufficient understanding that there were some climate change issues that we needed to address and one of the vehicles through which that could be done was regional planning.

The renewed recognition of climate change in the early-2000s did not immediately lead to substantial institutional transformation within the regional planning regime. Instead, the storyline that recognized climate change as a planning issue provided an institutional basis for two further storylines. Each framed institutional thinking on the perceived value and applicability of responding to climate change through planning with either mitigation or adaptation. The storylines are examined next. Particular attention is paid to the effects that regional stresses related to climate change had in conditioning institutional preferences for either response as 
preferred. The emergence of climate change as a transformative stressor and the subsequent institutional prioritization of adaptation rather than mitigation are of particular note.

Storyline 2: Mitigation should be the principal planning response to climate change stresses

Responding to climate change through mitigation of greenhouse gas emissions has been a significant institutional issue globally since the 1990s and has substantially influenced climate change discourse (Steffen 2009, Schipper 2007). Mitigation began to gain substantial attention within the SEQ regional planning regime in the early-2000s. The institutional storyline discussed above depicted climate change response as a regional planning issue, but decisions still needed to be made concerning the nature of appropriate responses through planning. Some institutional actors in SEQ regional planning were becoming cognizant of international literature that focused on mitigation and began to advocate for regional scale planning responses to climate change through mitigation. The Planning Institute of Australia also began to advocate in respect of mitigation. Interview Respondent IR6, a Queensland State government policy advisor, discussed the emergence of mitigation within institutional discourse:

Mitigation was recognized by some of the people that were tapped into the international literature and there was a recognition that we needed to do it in SEQ. There was also what was happening in Australia with the planning institute and what was happening internationally.

Notwithstanding the emergence of mitigation as a subject of institutional discourse, there was a persistent institutional perception in SEQ regional planning at the time which doubted the capacity of planning to respond to climate change through mitigation. Consequently, there was initial reluctance to establish mitigation as a tenet of regional planning governance. Lobbying from community and environmental groups disrupted this institutional inertia around 2003/4. A campaign had developed over a number of years and galvanized regional environmental groups, who began to use reports and models to demonstrate the impacts that climate change could have on SEQ. A select number of actors from the community sector were able to present their case to peak planning agencies within SEQ regional planning at the time. Interview Respondent IR6 noted:

There was large stakeholder enthusiasm for mitigation...and so it was seen [within regional planning] as quite an imperative to embrace. There was very, very strong public support for mitigation actions. This was a validation that key stakeholders felt that way.

The extent of stakeholder support for responding to climate change through mitigation, coupled with international debate focused on the issue, led to the emergence of an institutional storyline that viewed mitigation as the principal regional planning response to climate change in SEQ. Applied to the transformative stressors model, it may be argued that the emergence of this particular storyline was not related to direct climate change impacts, but was rather a response to stakeholder concern based on the potential for future regional stresses linked to climate change impacts. Whilst climate 
change began to gain greater institutional acceptance as a planning issue, it was not recognized as a transformative stressor, principally because of a lack of clear evidence linking climate change with specific regional impacts in SEQ. Moreover, some institutional actors, along with members of the public, were unconvinced of the reality of human induced climate change. Interview Respondent IR1 spoke to this point:

There was a perception in the early-2000s that extreme weather events were not unusual in SEQ. Climate change was not viewed as a major contributing factor at the time.

A consequence of this was some institutional uncertainty in respect of how and whether contemporary regional planning governance could limit future climate change impacts by prioritizing mitigation. The efficacy of planning-led mitigation was questioned by some actors in SEQ regional planning. Nonetheless, the mitigation storyline became strong enough to prompt incremental institutional transformation, leading to mitigation becoming part of regional planning governance. This occurred primarily through statutory policies in subsequent regional plans. These focused on densification, reducing building energy demand, urban consolidation, prioritizing subtropical design standards and increasing public transport provision (OUM, 2005; DIP, 2009a, 2009b).

Mitigation continues to feature as a planning response to climate change in SEQ, but the storyline that depicts it as the principal planning response now has diminished institutional traction. It began to diminish around 2006, when a series of direct and indirect climate change stresses began to manifest in SEQ. These impacts acted as trigger events and firmly established climate change as a transformative stressor for planning in SEQ. The need to respond through climate adaptation consequently became a new and dominant storyline and propelled climate adaptation onto the institutional planning agenda ahead of mitigation. The next section discusses these developments and their institutional significance.

Storyline 3: Climate change is an emergency planning issue for SEQ and climate adaptation is a vital response

Climate change became established as a transformative stressor for planning in SEQ in the mid-2000s. Three trigger events occurred in close succession, leading to a substantial strengthening of institutional recognition and acceptance of climate change as a phenomenon likely to create serious social, environmental and economic stresses for SEQ. The existing institutional storyline, which understood mitigation as the principal response strategy for planning, became secondary to a new and dominant storyline once climate change fully manifested as a transformative stressor. The new storyline focused on climate change adaptation as an emergency planning issue for SEQ and understood adaptation as a vital planning response.

The first trigger event that increased institutional focus on climate change as an immediate issue, requiring response through adaptation in SEQ, was the extensive political debate on adaptation at the national level in Australia. Climate adaptation became a key topic of attention at federal level in 2004, following the Commonwealth government's announcement of a national climate change adaptation program. The 
program was developed as a response to growing scientific evidence that mitigation alone would not be sufficient to manage to climate change impacts already made inevitable by historic emissions (COAG, 2007). The Commonwealth government's announcement of a national climate change adaptation program started a process of assessing national climate change risk and vulnerability, so that appropriate adaptation strategies could be generated. Responding the climate adaptation through planning was a central issue of discussion.

The increasing institutional focus on adaptation at the national level quickly filtered down to the state level in Queensland. The debates on adaptation at the national and state levels contributed to the emergence of a new institutional storyline that recognized the necessity and immediacy of adaptation as a vital issue for regional planning in SEQ. Adaptation was becoming understood as a contemporary necessity because the limitations of mitigation, especially in terms of delivering short-term outcomes, were becoming more widely appreciated. The Queensland State government recognized the rising profile of adaptation and began to look closely at how regional planning might respond to climate change through planning governance focused on adaptation in SEQ. Interview Respondent IR6, Queensland State government policy advisor, addressed this point:

Orders [were issued] by the highest levels of State government that climate change adaptation must be dealt with through regional planning.

Interview Respondent IR2 also spoke to the point:

A general awareness [of adaptation] was starting to come through government. These issues were starting to fall from the top. The Queensland government was starting to generally take a bigger interest in terms of climate change.

A second trigger event compounded institutional recognition of climate change as a transformative stressor and added further weight to the storyline that saw adaptation as an emergency issue for SEQ. This was the identification by the Intergovernmental Panel on Climate Change (IPCC), in their Fourth Assessment Report (AR4), that SEQ was one of the six areas most vulnerable areas to climate change in Australia (Hennessey et al., 2007, page 525). The IPCC predicted that climate change impacts in SEQ during the current century would include inland storm surges, reductions in water availability, increased coastal and inland inundation, sea level rises of up to $0.79 \mathrm{~m}$ over current levels and an increase in the number of days with temperatures in excess of $35^{\circ} \mathrm{C}$ (Hennessey et al., 2007, page 525). This triggered substantial institutional alarm in SEQ, as it became apparent that climate change impacts would compound existing severe weather events and natural hazards, including bushfires, inland flooding and coastal storm surges. The SEQ region, already challenged by significant development pressures and existing natural hazards, was now clearly identified as facing nascent and potentially severe climate change stresses. This led to further institutional concern and accelerated recognition and acceptance of climate change as a transformative stressor for SEQ.

The Fourth Assessment Report added substantial weight to the storyline of adaptation as an emergency planning issue for SEQ and removed ambiguity that climate 
change was a major challenge for the region. It added scientific certainty to regional vulnerabilities related to climate change and confirmed the need to respond through regional planning activities. This factor, combined with wider debates on the necessity of adaptation, further emphasized the nature of adaptation as an emergency planning issue in SEQ in the context of stresses related to climate change. Institutional responses through the emergence of a storyline, which accepted this new knowledge, consequently gained further traction. Interview Respondent IR6 noted:

I feel certain that it was the IPCC AR4...I think that was very confirming that the terminology of adaptation was accepted. The findings removed any ambiguity that climate change was a major issue for the region. There was legitimacy in SEQ that we needed to do adaptation. [It] gave voice to reasoning for planning responses.

Interview Respondent IR11 also spoke to the connection between the findings of AR4 and institutional acceptance of the need for planning-led adaptation:

It was interesting to have it confirmed [by the IPCC] that the region was very vulnerable to climate change. A concern was that the insurance industry would start to do make decisions on behalf of government if the government didn't do something about adaptation.

The third significant event that added to the emerging storyline that supported planning-led adaptation was the near decade-long drought that had severely affected SEQ during the 2000s. Severe drought conditions became established in SEQ in the early-2000s and lasted for most of that decade. Water availability fell substantially year on year, leading to severe restrictions on water use across sectors. This led to widespread recognition of the drought as a crisis issue. The severity of the drought influenced institutional thinking within the regional planning regime. For example, policymakers began to realize that the rapid population growth that had been ongoing in the region since the 1970s was heavily contingent on water availability. An increasing population, coupled with decreasing water supplies, was of substantial institutional concern because of its potential to create ongoing economic, social and environmental stresses. This led to a greater urgency in terms of responding to limited water availability through planning. Interview Respondent IR8, a Coordinator of the SEQ Regional Organization of Councils (SEQROC) from 1994-2006, suggested that:

[The drought] highlighted that population growth had been so reliant on water supply. The association of that with the arguments about adaptation started to hit home. Some people recognized that we needed to respond through better planning and adaptation.

Whilst the drought was never directly connected either scientifically or popularly to climate change, it did prompt shifts in public and political perceptions. Some people began to view the drought as illustrative of potential future scenarios under climate change. This thinking also took hold within the institutional setting of regional planning. Institutional attention again focused on the need for adaptation and the necessity of developing adaptation responses through planning that could be used for similar events into the future. This created further traction for the storyline that saw climate change adaptation as an emergency issue for planning in SEQ. Interview 
Respondent IR7, a regional planning policy advisor in SEQ and Chair of Council of Australian Governments (COAG) Working Group on Climate Change Adaptation, stated that:

It was always going to be a challenge to say that this drought is proof of climate change or it isn't... what you could say was that it was a picture of a potential climate change future.

The drought in SEQ linked to the substantial government debates on climate adaptation and to the publication of the Intergovernmental Panel on Climate Change (IPCC) Fourth Assessment Report (AR4), which identified the region as highly vulnerable to climate change impacts. This created a confluence of impacts, which marked the manifestation of climate change as a transformative stressor. That led to institutional recognition and acceptance of climate change as a transformative stressor within the SEQ regional planning regime. A dominant institutional storyline that climate change adaptation is an emergency issue for planning in SEQ became established as a result, leading to institutional transformation. Governance responses focused on adaptation consequently began to emerge from 2009. This was very significant, because adaptation had not featured as planning concern prior to this time. Policy responses appeared in the statutory South East Queensland Regional Plan 2009-2031, designed to adapt to climate change impacts including sea level rise, riverine flooding, storm surges and heat waves (DIP, 2009a, page 44). Related implementation actions featured in the complementary Draft SEQ Climate Change Management Plan 2009 (DIP, 2009b). The statutory nature of regional planning in SEQ meant that subsequent planning activities and processes overseen by local councils had to correspond with policies and objectives established at the regional scale. The Queensland Government also became a key partner in the South East Queensland Climate Adaptation Research Initiative (SEQCARI). The project ran from 2009-2012 and was led by the Commonwealth Scientific and Industrial Research Organization (CSIRO). It was designed to examine vulnerabilities in the region and develop a suite of adaptation strategies. Developing options for adapting to climate change through planning was a specific project focus.

The emergence of the adaption storyline represents a significant institutional transformation within the SEQ regional planning regime. Perceptions of climate change as a future problem were displaced. The new storyline accepted climate change as a real and contemporary issue for planning, requiring near-term institutional responses through planning governance focused on climate adaptation. This shift in institutional thinking and narrative appears intrinsically linked to the emergence of climate change as a transformative stressor in SEQ. This generated an institutional acceptance of climate adaptation as a necessary and immediate response strategy and a vital component of planning governance. The emergence of the storyline appears directly connected to three trigger events, which cumulatively compelled institutional transformation. In short, adaptation may not have gained strong institutional traction were it not for escalating and intensifying stresses that led to institutional recognition and acceptance of climate change as a transformative stressor within SEQ regional planning.

Future prospects for climate change storylines in $S E Q$ 
The regional planning agenda in SEQ was an initiative of successive Labor party State governments who held power from 1990-2012, with a short exception from 1996-1998. There was a state election in Queensland in March 2012 and Labor lost office to the Liberal/National Party (LNP) in a landslide. The LNP State government quickly sought to re-orientate planning activity across the state. The new State government released Temporary State Planning Policy 2/12 in August 2012 (DSDIP, 2012). The statutory document seeks to remove many regulatory barriers that are perceived to impede economic growth, particularly in the agricultural, tourism, mining, commercial and industrial sectors. The State government's key aim now appears to be for planning activity to promote economic growth. All planning activities and processes across Queensland, including regional planning governance in SEQ, must now begin to align with the provisions of Temporary State Planning Policy 2/12. The new policy does not address climate change directly. The only area of the policy that may be construed as connected to climate change is a brief mention of resilience to natural hazards as a potential planning issue. The new State government also cancelled many existing climate change response programs and policies across the state and diluted of a suite of environmental legislation on the basis that it impedes development. This may indicate that the new State government regards economic development demand as a transformative stressor with greater and more immediate impacts than climate change. This appears to be illustrated by the prevalence of storylines focused on economic growth within Temporary State Planning Policy 2/12.

The regional planning regime in SEQ still has statutory force at present. There remains scope for continuing institutional responses to climate change to be articulated through existing and future storylines, even if the LNP government appears unprepared to accept climate change as a transformative stressor. Two of the three institutional storylines of climate change discussed in this paper may continue under the new Queensland government. The first is the storyline that depicts climate change as an important regional planning challenge, requiring institutional response through planning processes. The new State government appears disinclined to respond to climate change through regional planning and so may distance itself from the storyline and seek to limit its institutional traction within the regional planning system. However, the storyline initially held stronger traction within local councils in SEQ and it is possible that local councils, rather than State government, will seek to maintain institutional focus on climate change over the coming years. This may be particularly likely if they become more concerned about their capacity to respond to future climate change stresses within their functional areas. Moreover, future severe weather events may construed as climate change impacts, forcing the State government to re-examine institutional acceptance of climate change as a transformative stressor.

The second storyline that may continue depicts climate change as an emergency planning issue for SEQ and adaptation as a vital response. It may persist even if there is a decline in political or institutional acceptance of potential causation between the impacts of severe weather or natural disasters and climate change. Impacts in SEQ may therefore be institutionally responded to through regional planning governance, even if they are willfully or mistakenly attributed to natural occurrences or climate variability. However, this storyline, or any future storylines associated with climate adaptation, may refer to 'resilience to natural hazards' rather than 'climate adaptation'. The use of 'resilience to natural hazards' would more closely reflect terminology used by the 
current State government in Temporary State Planning Policy 2/12 (DSDIP, 2013). A change in terminology for strategic or political reasons could potentially occur without diminishing institutional acceptance of the need for regional planning governance in SEQ to respond to climate change as a transformative stressor through adaptation. The other storyline discussed in this paper, which depicts mitigation of greenhouse gases as the principal planning response to regional climate change stresses, began to diminish around 2006 and had limited institutional traction by 2012. As such, it appears unlikely to be affected by the change in State government.

\section{Summary and conclusions}

This paper has sought to add to existing scholarly conversations in Environment and Planning $C$, which focus on responses to climate change through planning governance, as well as the role of storylines in framing institutional responses (Bulkeley, 2000; Fisher, 2012; Lovell, Bulkeley and Owens, 2009). It specifically sought to provide new insights into the intersection of these processes with the conceptual model of storylines presented by Hajer $(1993,1995)$. It drew upon institutional theory within the social sciences and demonstrated a new conceptualization of institutional transformation, enacted in response to the manifestation of transformative stressors. Hajer's (1993; 1995) conceptual model of 'storylines' was applied via the 'transformative stressors' model of institutional transformation proposed by Matthews (2012). It was argued that institutional recognition, acceptance and responses to transformative stressors may be articulated through storylines. It was further argued that institutions can interpret and respond to transformative stressors through storylines, as actors use storylines to create descriptions of particular transformative stressors and their impacts.

The conceptual perspectives used by this paper were applied to an empirical examination, which focused on the statutory regional planning regime in South East Queensland (SEQ), Australia. It identified and critically discussed institutional responses to the manifestation of climate change as a transformative stressor in SEQ. Three institutional storylines were identified and examined. The first storyline understood climate change as an important regional planning challenge for SEQ requiring response through planning activities, processes and instruments. The storyline became institutionally accepted in SEQ regional planning in the early-2000s. It provided an institutional context where climate change was recognized as a regional planning issue. As such, it was central in facilitating two other storylines focused on responding to climate change, first through planning-led mitigation and subsequently through planning-led adaptation.

A second storyline of climate change in SEQ focused on mitigation as the principal planning response. The storyline began lose institutional support from 2006, as three trigger events and marked the manifestation of climate change as a transformative stressor in SEQ. That prompted an institutional transformation, leading to an institutional acceptance that regional planning must respond to climate change through the development and enactment of new planning governance. These new institutional priorities clustered within a third storyline that understood climate change as an emergency planning issue for SEQ and planning-led adaptation as a vital institutional response. 
This paper provided new conceptual and empirical insights into how new forms of governance may be developed and enacted when institutions are confronted with new or emerging forms of stress. It specifically focused on institutional responses to climate change and how storylines can frame institutional thinking and governance outcomes. It offers useful conceptual and empirical insights in this regard. Its focus on the case of regional planning in SEQ is timely, as it offers insights into the circumstances under which changes to planning governance occurred in a region that is highly vulnerable to climate change stresses. The SEQ regional planning regime is an early adapter to climate change impacts, principally because transformative stresses associated with climate change manifested relatively early in the region. The experiences of regional planning in South East Queensland in responding to climate change through institutional transformation, leading to new planning governance, provide important insights for scholarship and planning practice. These insights are especially valuable because they focus on climate change, a phenomenon with significant contemporary and nascent implications for policy and governance and which are already impacting at the interface between society, the economy and the environment.

\section{References}

Abbott J, 2009 "Planning for Complex Metropolitan Regions: A Better Future or a More Certain One?" Journal of Planning Education and Research 28 503-517

Alexander E R, 2005 “Institutional Transformation and Planning: From Institutionalization Theory to Institutional Design" Planning Theory 4(3) 209-222

Bulkeley H, 2000 "Discourse Coalitions and the Australian Climate Change Policy Network" Environment and Planning C: Government and Policy 18 727-748

Bulkeley H, Schroeder H, Janda K, Zhao J, Armstrong A, Yi Chu S, Ghosh S 2009 "Cities and Climate Change: The role of institutions, governance and urban planning - Report prepared for the World Bank Urban Symposium on Climate Change" World Bank, Geneva

COAG [Council of Australian Governments], 2007 "National Climate Change Adaptation Framework" Council of Australian Governments, Canberra

Cortell A P, Peterson S, 1999 "Altered States: Explaining Domestic Institutional Change" British Journal of Political Science 29 177-203

CSIRO [Commonwealth Scientific and Industrial Research Organization], 2011 "Climate Change Science and Solutions for Australia" Commonwealth Scientific and Industrial Research Organization, Melbourne

CSIRO [Commonwealth Scientific and Industrial Research Organization], 2012 "State of the Climate Report 2012" Commonwealth Scientific and Industrial Research Organization, Melbourne

DIP [Department of Infrastructure and Planning], 2009a "South East Queensland Regional Plan 2009-2031" Queensland Government, Brisbane

DIP [Department of Infrastructure and Planning], 2009b "South East Queensland Climate Change Management Plan 2009-2031" Queensland Government, Brisbane

DSDIP [Department of State Development, Infrastructure and Planning], 2012 "Temporary State Planning Policy 2/12" Department of State Development, Infrastructure and Planning, Brisbane

Fisher S, 2012 "Policy Storylines in Indian Climate Politics: Opening New Political Spaces" Environment and Planning C: Government and Policy 30 109-127

Flick U, 2008 An Introduction to Qualitative Research (Sage, London) 
Forester J, 1989 Planning in the Face of Power (University of California Press, California)

Garnaut R, 2008 Garnaut Climate Change Review: Report to the Commonwealth, State and Territory Governments of Australia (Cambridge University Press, Port Melbourne)

Giddens A, 1984 The Constitution of Society: Outline of the Theory of Structuration (Cambridge University Press, Cambridge)

Gleeson B, 2008 "Waking from the Dream: An Australian Perspective on Urban Resilience" Urban Studies 45 2653-2668

Hajer M, 1993 "Discourse Coalitions and the Institutionalization of Practice: The Case of Acid Rain in Great Britain" in The Argumentative Turn in Policy Analysis and Planning Eds F Fischer, J Forester (Routledge, London) pp 43-76

Hajer M, 1995 The Politics of Environmental Discourse, Environmental Modernisation and the Policy Process (Clarendon Press, Oxford)

Hall P A, Taylor R, 1998 "Political Science and Three New Institutionalism" in Institutions and Social Order Eds K Soltan, E M Uslaner, V I Haufler (University of Michigan Press, Ann Arbour)

Healey P, 1998 "Building Institutional Capacity through Collaborative Approaches to Urban Planning" Environment and Planning A: Environment and Planning 30(9) 15311546

Healey P, 2006 "Transforming Governance: Challenges of Institutional Adaptation and a New Politics of Space" European Planning Studies 14(3): 299-320

Hennessy K, Fitzharris B, Bates BC, Harvey N, Howden SM, Hughes L, Salinger MJ, Warrick R, 2007 "Australia and New Zealand" in Climate Change 2007: Impacts, Adaptation and Vulnerability. Contribution of Working Group II to the Fourth Assessment Report of the Intergovernmental Panel on Climate Change Eds M L Parry, O F Canziani, J P Palutikof, P J van der Linden, C E Hanson (Cambridge University Press, Cambridge).

Hodgson G M, 2006 "What are Institutions?" Journal of Economic Issues 40(1): 1-25

Hogan J, 2006 "Remoulding the Critical Junctures Approach" Canadian Journal of Political Science 39: 657-679

IPCC [Intergovernmental Panel on Climate Change], 2012 "Managing the Risks of Extreme Events and Disasters to Advance Climate Change Adaptation" Eds. C B Field, V Barros, T F Stocker, D Qin, D J Dokken, K L Ebi, M D Mastrandrea, K J Mach, G K Plattner, S K Allen, M Tignor, P M Midgley (Cambridge University Press, Cambridge)

IPCC [Intergovernmental Panel on Climate Change], 2007 "Climate Change 2007: Synthesis Report, Contribution of Working Groups I, II and III to the Fourth Assessment Report of the Intergovernmental Panel on Climate Chang" Eds R K Pachauri, A Reisinger (Cambridge University Press, Cambridge)

Kingston C, Caballero G, 2009 "Comparing theories of institutional change" Journal of Institutional Economics 5: 151-180

Levi M, 1990 "A Logic of Institutional Change" in The Limits of Rationality Eds K S Cook, M Levi, (Chicago University Press, Chicago) pp 402-418

Lovell H, Bulkeley H, Owens S 2009 “Converging Agendas? Energy and Climate Change Politics in the UK" Environment and Planning C: Government and Policy 27: 90-109

Low N, Gleeson B, Rush E, 2003 “Making Believe: Institutional and Discursive Barriers to Sustainable Transport in Two Australian Cities" International Planning Studies 8(2): 93-114

March J, Olsen J, 2005 “Institutional Perspectives on Political Institutions” Governance 9: 
247-264

Matthews T, 2012 "Responding to Climate Change as a Transformative Stressor through Metro-Regional Planning" Local Environment: The International Journal of Justice and Sustainability 17(10): 1089-1103

North D C, 1990 Institutions, Institutional Change and Economic Performance (Cambridge University Press, Cambridge)

North D C, 1993 “Five Propositions about Institutional Change: in Explaining Social Institutions Eds J Knight, I Sened (University of Michigan Press, Ann Arbor)

OUM [Office of Urban Management], 2005 "South East Queensland Regional Plan 20052026" Queensland Government, Brisbane

Patton M, 1990 Qualitative Evaluation and Research Methods (Sage, Newbury Park) Sarantakos S, 2005 Social Research - $3^{\text {rd }}$ Edition (Palgrave MacMillan, New York) Schipper E L F, 2007 "Climate Change Adaptation and Development: Exploring the Linkages", Tyndall Centre for Climate Change Research, Norwich

Steffen W, 2009 "Climate Change 2009: Faster Change and More Serious Risks" Australian Government Department of Climate Change, Canberra

Stern N, 2006 "Stern Review on The Economics of Climate Change" HM Treasury, London

Yanow D, 2000 Conducting Interpretive Policy Analysis (Sage, London)

Young O R, 1999 Governance in World Affairs (Cornell University Press, Ithaca)

Young O R, 2002 The Institutional Dimensions of Environmental Change: Fit, Interplay and Scale (MIT Press, Cambridge)

Young O R, 2010 "Institutional Dynamics: Resilience, Vulnerability and Adaptation in Environmental and Resource Regimes" Global Environmental Change 20: 378-385 